\title{
Temporal change in mKIAA gene expression during the early stage of
} retinoic acid-induced neurite outgrowth.

Kazuhide Imai ${ }^{\text {a }}$, Makoto Kawai ${ }^{\text {a }}$, Mitsuhiro Tada ${ }^{\mathrm{b}}$, Takahiro Nagase ${ }^{\mathrm{c}}$, Osamu

$$
\text { Ohara }^{\mathrm{c}, \mathrm{d}} \text {, Hisashi Koga }{ }^{\text {a, }{ }_{*}}
$$

${ }^{a}$ Chiba Industry Advancement Center, 2-6 Nakase, Mihama-ku, Chiba 261-7126,

\section{Japan}

${ }^{b}$ Division of Cancer-Related Genes, Molecular Biology Laboratory, Institute for Genetic Medicine, Hokkaido University, N-15 W-7 Kita-Ku, Sapporo 060-0815, Japan

${ }^{c}$ Kazusa DNA Research Institute, 2-6-7 Kazusa-Kamatari, Kisarazu, Chiba 292-0818, Japan

${ }^{d}$ RIKEN Yokohama Institute, 1-7-22 Suehiro-cho, Tsurumi-ku, Yokohama City, Kanagawa 230-0045, 8, Japan

Key words: KIAA; Mouse; Microarrays; RT-PCR; Pathway

\begin{abstract}
Abbreviations: KIAA, "KI" stands for "Kazusa DNA Research Institute" and "AA" are reference characters; RA, all-trans-retinoic acid; RARE, retinoic acid-responsive element; DMEM, Dulbecco's modified Eagle's minimum essential medium; FBS, fetal bovine serum

*Address for Correspondence: Tel, +81 43852 3919; Fax, +81 43852 3918; e-mail,hkoga@kazusa.or.jp
\end{abstract}




\section{Abstract}

mKIAA genes are mouse counterparts of human KIAA genes, which were isolated in our cDNA project and were functionally unknown at the time they were sequenced. Because KIAA/mKIAA genes were isolated mainly from cDNA libraries derived from brain tissues, they are thought to be important for the organization and function of the brain. To investigate the participation of mKIAA genes in neuronal phenomena, we analyzed retinoic acid-induced neurite outgrowth using an mKIAA oligonucleotide microarray. Focusing on the early stage of this outgrowth phenomenon, we analyzed temporal gene expression changes 1-24 $\mathrm{h}$ after treatment with retinoic acid and found several change patterns in 38 mKIAA genes. Among them, six were upregulated at $3 \mathrm{~h}$ and subsequently returned to the steady state. Supposing that these genes had important roles, we performed semi-quantitative RT-PCR analysis and confirmed the existence of temporal expression patterns in two genes (mKIAA0182 and mKIAA1039). Further computational analysis of the 38 genes enabled us to find the cellular pathway associated with 6 of them with high confidence. These results indicate that some mKIAA genes are apparently relevant to retinoic acid-induced neurite outgrowth. 


\section{Introduction}

We have been conducting a human cDNA sequencing project since 1994 to accumulate information about the long cDNAs that encode large proteins (Nomura et al., 1994; Nakajima et al., 2002). We focused our limited sequencing capacity on long cDNAs, because the functions of many large proteins may be related to higher-order cell functions such as neuronal differentiation. Further concentrating on brain functions, we constructed cDNA libraries principally derived from adult and fetal human brains, and as a result identified more than 2000 genes (KIAA genes) unknown at the time they were sequenced. Since December 2001, we have been working on the next step, collecting and characterizing cDNAs that encode mouse counterparts of human KIAA proteins (mKIAA). Mouse counterparts were used in light of the legal and ethical restrictions on the use of human material. Thus far we have already reported approximately 2000 mouse mKIAA cDNAs and the tissue-specific expression of the genes using mKIAA cDNA microarrays (Okazaki et al., 2002a; Okazaki et al., 2003a; Okazaki et al., 2003b; Koga et al., 2004; Okazaki et al., 2004a; Okazaki et al., 2004b). Although cDNA microarray analysis has revealed nearly half of our collection of genes expressed predominantly in the adult brain, the detailed 
functional significance of each gene remains to be elucidated.

To annotate the function of each KIAA/mKIAA gene, we have attempted to examine temporal changes in mKIAA gene expression during retinoic acid-induced neurite outgrowth of Neuro2A cells; this outgrowth is a well-known form of cancer cell differentiation (Shea et al., 1985; Riboni et al., 1995). All-trans-retinoic acid (RA), a retinoid, is a biologically active metabolite derived from vitamin A. RA plays an essential role in embryogenesis by modulating the growth and differentiation of a variety of cell types, particularly in the developing nervous system (Marshall et al., 1996; Schilling and Knight, 2001). The results of many experimental approaches have suggested a regulatory role for RA in the development of the nervous system. Although all the evidence to date supports the notion that RA is essential for neuronal growth and differentiation, the molecular events occurring after interaction between RA and retinoid receptors are not completely understood.

In the present study, we report mKIAA genes downstream of RA signaling isolated by oligonucleotide microarray analysis of retinoic acid-treated Neuro2A cells. Moreover, using pathway analysis software, we demonstrate the importance of the modulation of the network of cell death and morphology. 


\section{Materials and Methods}

\subsection{Cell culture and retinoic acid treatment}

Murine neuroblastoma cell line Neuro2A was cultured in DMEM (Invitrogen, Carlsbad, CA) supplemented with $10 \% \mathrm{FBS}$ at $37^{\circ} \mathrm{C}$ under $5 \% \mathrm{CO}_{2}$. To induce neurite outgrowth, the cells were plated at a density of $3.8 \times 10^{3}$ cells $/ \mathrm{cm}^{2}$. After $48 \mathrm{~h}$, the medium was replaced with $2 \%$ FBS-DMEM containing $20 \mu \mathrm{M}$ all-trans-retinoic acid (RA), and the incubation was continued for different periods up to $24 \mathrm{~h}$. The treatment was independently performed four times.

\section{2. $m R N A$ preparation}

Total RNAs were isolated from the Neuro2A cells using TRIZOL (Invitrogen) reagent. The poly (A)+ RNAs were isolated from the total RNAs using the $\mu$ MACS mRNA Isolation Kit (Miltenyi Biotec, Bergisch Gladbach, Germany) according to the manufacturer's protocol. The quantities and qualities of the RNAs were measured by electrophoresis using the Agilent 2100 Bioanalyzer and RNA 6000 Nano Kit (Agilent Technologies, Palo Alto, CA).

\section{3. mKIAA oligonucleotide microarray}

We generated a mouse mKIAA oligonucleotide microarray on which were spotted

511 oligonucleotides, consisting of 486 mKIAA genes, 3 mKIAA-paralogous 
genes, $1 \mathrm{mFLJ}$ gene, 7 positive controls (housekeeping genes), and 14 negative controls (plant chloroplast genes: 1 spot of psaA, 1 spot of psbB, and 12 spots of rbcL). The oligonucleotides were designed according to four conditions: 1) their lengths were between 65 and $75 \mathrm{bp}$; 2) the melting temperatures (Tm) were between 70 and $80^{\circ} \mathrm{C}$ ( $\mathrm{Tm}$ was calculated by the \%GC method); 3) the GC contents were between 45 and 65\%; and 4) the uniqueness of the sequences against UniGene entries was confirmed by ProbeQuest software (Dynacom, Chiba, Japan). The oligonucleotides were synthesized by Nihon Gene Research Laboratories (Miyagi, Japan) and $50 \mu \mathrm{M}$ of the solution (in DSP0050 spotting solution [Matsunami, Osaka, Japan]) was singly spotted on glass slides using an ink-jet spotter (NGK Insulators, Aichi, Japan). Before hybridization, the arrays were treated with blocking buffer $(1 \% \mathrm{BSA}, 4 \times \mathrm{SSC}, 0.5 \% \mathrm{SDS})$ at $42^{\circ} \mathrm{C}$ for 45 min, washed twice with sterile water, and then immediately dried by blown air.

\subsection{Microarray hybridization}

mRNAs $(1 \mu \mathrm{g})$ were labeled with Cy5 dye using the BD PowerScript Fluorescent Labeling Kit (BD Biosciences Clontech, Palo Alto, CA) according to the manufacturer's protocol (except for a partial modification of the priming procedure, in which we annealed $0.36 \mu \mathrm{g}$ random nonamer at $42^{\circ} \mathrm{C}$ for $90 \mathrm{~min}$ ). 
The labeled cDNAs were purified by using a QIAquick PCR Purification Kit (Qiagen, Valencia, CA). The labeling efficiency and the quantity of incorporated Cy5 dye were calculated by UV/Vis spectrophotometry. After the cDNAs were mixed with $2 \mu \mathrm{g}$ mouse Cot-1 DNA and $2 \mu \mathrm{g}$ poly dA, they were precipitated by ethanol. The precipitant was dissolved in $40 \mu$ hybridization buffer $(50 \%$ formamide, $5 \times \mathrm{SSC}, 0.5 \% \mathrm{SDS}$ ), denatured at $100^{\circ} \mathrm{C}$ for $5 \mathrm{~min}$, and incubated at $42^{\circ} \mathrm{C}$ for $15 \mathrm{~min}$. Hybridization was carried out at $42^{\circ} \mathrm{C}$ for $16 \mathrm{~h}$ using the Array Booster (Advalytix, Brunnthal, Germany), which was expected to improve the hybridization efficiency. After hybridization, the arrays were washed twice with $2 \times \mathrm{SSC} / 0.1 \% \mathrm{SDS}$ buffer at $60^{\circ} \mathrm{C}$ for $10 \mathrm{~min}$ and then twice with $0.2 \times \mathrm{SSC} / 0.1 \%$ SDS buffer at $60^{\circ} \mathrm{C}$ for $10 \mathrm{~min}$. After further soaking at RT in $0.05 \times \mathrm{SSC}$ buffer, the slides were immediately desiccated by blown air and scanned on the FLA-8000 Fluorescent Image Analyzer (Fujifilm, Tokyo, Japan). The fluorescence intensities were quantified by Phoretix Array software (Nonlinear Dynamics, Newcastle upon Tyne, UK). The fluorescence intensities of empty spots were recorded simultaneously for use as background signals. All the raw data described in this study were deposited into the Gene Expression Omnibus (http://www.ncbi.nlm.nih.gov/geo/) under the accession number GPL1964. 


\subsection{Data analysis}

The quantified raw data were statistically analyzed using Visual Mining Studio software (Mathematical Systems, Tokyo, Japan). The data analyses were executed through the following steps: 1) the data were normalized by the median intensity of each array; 2) the mean value ( $\mu \mathrm{i})$ and standard deviation $(\delta \mathrm{i})$ of each gene were calculated from eight spots (four replicate experiments), and a few data ( $>$ or $<\mu \mathrm{i} \pm 2 \delta \mathrm{i}$ ) were excluded from further analysis; 3 ) mean values that were lower than those of plant genes (negative control) were excluded because of their unreliability; 4) fold changes of each gene expression were calculated against $0 \mathrm{~h}$, and statistical significance was examined using the Welch modified two-sample t-test and the Wilcoxon test; and 5) changes $>1.7$ and probabilities $<0.05$ were the criteria for the selection of candidate genes. Hierarchical clustering was performed by Ward's method (de Brevern et al., 2004) using Visual Mining Studio software. The distance matrix between all the genes is calculated by the following formula: $D\left(C_{1}, C_{2}\right)=E\left(C_{1} \mathrm{U} C_{2}\right)-E\left(C_{1}\right)-E\left(C_{2}\right), C_{1}$ and $C_{2}$ are two distinct genes, and $E(C i)=\sum_{x \varepsilon C i}\left(D\left(x, c_{i}\right)\right)^{2}$.

\subsection{Semi-quantitative RT-PCR}

First-strand cDNAs were synthesized in a manner similar to that described in 2.4. 
but without the coupling substrate (aminoallyl-dUTP). The concentrations of synthesized cDNA mixture were calculated by UV/Vis spectrophotometry and then diluted with TE. The final concentration of each cDNA was adjusted to 0.4 ng/ $\mu 1$ as a template. PCR reactions were then carried out using LA Taq (Takara, Siga, Japan). The cycling programs were changed according to the optimal conditions for each gene (Table 1). After the PCR reaction, 1/10 volume of 0.5 M EDTA was added to the reaction mixture. The amplified products were quantified using the Agilent 2100 Bioanalyzer and DNA500 Kit (Agilent Technologies). Similarly, Gapd (glyceraldehyde-3-phosphate dehydrogenase, GeneID: 407972) expression was assessed as an internal control and used for calibration of the mKIAA gene expression.

\subsection{Bioinformatics analysis of regulatory genomic regions}

The $100 \mathrm{~kb}$ 5'-upstream sequence (NC_000074, 119838227-119938226) and intron 1 (65,907 bp, 119938513-120004419) of Gse1 (genetic suppressor element 1, GeneID: 382034, identical to mKIAA0182 but extending in the 5'-direction for $850 \mathrm{bp}$ ) were retrieved from Entrez Gene, which is one of the Entrez databases constructed in 2004 to replace the widely known and used LocusLink database (http://www.ncbi.nlm.nih.gov/entrez/query.fcgi?db=gene). Likewise, the $100 \mathrm{~kb}$ 
5'-upstream sequence (NC_000077, 74037827-74137826, complementary) and intron 1 (283 bp, 74037454-74037736, complementary) of Garnl4 (GTPase activating RANGAP domain-like 4, GeneID: 380711, identical to mKIAA1039 but extending in the 5'-direction for $640 \mathrm{bp}$ ) were retrieved. In each sequence, a direct repeat of 'RGKTCA' ([R $=\mathrm{A}$ or $\mathrm{G}],[\mathrm{K}=\mathrm{T}$ or $\mathrm{G}]$ ) allowing a 0 - to 15-spacer (Mader et al., 1993) was searched using SKIPPER, a tree-based skipping string search algorithm implemented in $\mathrm{C}$ language. In addition, another possible RARE (5'-AAGGGTGGGGGTGGGCC-3') (Wang and Yen, 2004) was searched allowing three mismatches using an ambiguous string search algorithm, HYPERFINDIUB.

\subsection{Pathway analysis}

The gene accession numbers of 38 mKIAA genes were imported into Ingenuity Pathway Analysis software (Ingenuity Systems, Mountain View, CA). The pathway of cell death and morphology was selected with high confidence (probability $<0.0199$ ). The data were exported to another pathway analysis tool, PathwayAssist (Ariadne Genomics, Rockville, MD), and the graphical view was manually reconstructed. 


\section{Results}

\subsection{Oligonucleotide microarray analysis}

To annotate the functional significance of KIAA/mKIAA genes in neuronal phenomena, we analyzed the retinoic acid-induced neurite outgrowth of Neuro2A cells. Morphological changes started at $6 \mathrm{~h}$ after RA treatment, and more than $70 \%$ of the cells had distinct neurites at $96 \mathrm{~h}$ after the treatment (data not shown). We focused on early changes in gene expression, which had not been extensively studied, so the cells were sequentially harvested before the completion of neurite outgrowth $(0,1,3,6,12$, and $24 \mathrm{~h}$ after RA treatment).

Cy5-labeled cDNA probes were hybridized to mKIAA oligonucleotide microarrays (oligo arrays), and the data were statistically analyzed. Figure 1 shows the temporal and spatial gene expression patterns of the 38 mKIAA genes in which a fold change $>1.7$ was observed at at least one time point after RA treatment. Hierarchical clustering of these data was used to group genes with similar expression patterns. However, since several expression patterns were found, the genes were divided into two major groups. Eight genes belonged to an upregulated gene group while the remaining 30 belonged to a downregulated gene group. In the former group, mKIAA1209, encoding the pleckstrin 
homology domain at the $\mathrm{N}$-terminal, gradually increased its expression, whereas six mKIAA genes (mKIAA0182, mKIAA0338, mKIAA0647, mKIAA0835, mKIAA1039, and mKIAA1122) were upregulated at $3 \mathrm{~h}$ and subsequently returned to the steady state. In the latter group, eight mKIAA genes (mKIAA0005, mKIAA0059, mKIAA0171, mKIAA0312, mKIAA0664, mKIAA0670, mKIAA0719, and mKIAA845) gradually decreased their expression. These data indicate that many mKIAA genes are involved in the early stage of retinoic acid-induced neurite outgrowth, and that this phenomenon involves several patterns of temporal waves of gene expression.

\subsection{Semi-quantitative RT-PCR}

To confirm the oligo array results, we performed semi-quantitative RT-PCR for two genes (mKIAA0059 and mKIAA1209) that were temporally downregulated or upregulated, followed by RA treatment. Primer pairs were designed to span the introns so as to exclude the effect of possible contamination of pre-mRNA (Table 1). The relative gene expression changes assayed using RT-PCR were almost consistent with those of the oligo arrays (Fig. 2). Further focusing on genes that RA treatment quickly elicited, we also analyzed the six genes mentioned above that peaked at $3 \mathrm{~h}$ and then rapidly decreased after the treatment. 
Even in the RT-PCR, two of these genes (mKIAA0182 and mKIAA1039) showed similar temporal changing patterns (Fig. 2). The other four genes showed patterns similar to each other (mKIAA0338, mKIAA0647, mKIAA0835, and mKIAA1122), and the signal changes were lower than 1.7 -fold peaked at $3 \mathrm{~h}$ (1.6, $1.3,1.4$, and 1.4 , respectively, data not shown). The small differences in the results may be attributable to the differences between these two methods. Nonetheless, these results support the idea that at least these two genes are molecular switches that are elicited directly by RA and participate in neurite outgrowth of Neuro2A cells.

\subsection{Bioinformatics analysis in the regulatory genomic regions}

One way to address this idea is to search the retinoic acid-responsive elements (RAREs) in their regulatory genomic regions. We thus searched for a conventional (direct repeat [5'- A/GGT/GTCA -3'] that follows various spacers) (Mader et al., 1993) and a novel RARE (5'-AAGGGTGGGGGTGGGCC-3') (Wang and Yen, 2004) in $100 \mathrm{~kb}$ regions upstream of these genes and in the first introns. Unfortunately, we found neither of these RAREs in the proximity of putative initiation codons. The ggGGGTGGGGGTGGGCg sequence located at -3517 to -3501 bp and the RAREs in intron 1 of mKIAA0182 might be expected 
to confer this gene with retinoic acid responsiveness (Table 2). There are still possibilities for finding a bona fide initiation codon in regions further upstream. Alternatively, modified or novel RAREs (we searched only direct repeats having spacers within $15 \mathrm{bp}$ ) might be present in the proximity of the putative initiation codon.

\subsection{Cellular pathway analysis}

To identify the cellular pathways participating in the RA-induced neurite outgrowth, the 38 mKIAA regulated genes were mapped on manually curated pathways available in the Ingenuity database. Interestingly, six of the 38 mKIAA genes were mapped on the pathway of cell death and morphology (Fig.

3A). Since the probability of a gene pair being mapped was less than 0.0199 , the selection of this pathway is thought to be reliable. All six genes were temporally and synergistically downregulated (Fig. 3B). 


\section{Discussion}

In this study, we tried to functionally annotate mKIAA genes according to their roles in neuronal phenomenona, such as the retinoic acid-induced neurite outgrowth of Neuro2A cells, using mKIAA oligonucleotide microarrays. Consequently, we identified 38 mKIAA genes that change their expression rapidly (1-24 h) after RA treatment. A particularly dramatic example of the temporal gene expression patterns was observed in six mKIAA genes transiently upregulated at $3 \mathrm{~h}$ after RA treatment. Since these genes seemed to be molecular switches elicited directly by RA and seemed to participate in the neurite outgrowth of Neoro2A cells, we performed semi-quantitative RT-PCR analysis and confirmed the temporal gene expression patterns of two mKIAA genes (mKIAA0182 and mKIAA1039).

mKIAA0182, which is identical to Gse1 (genetic suppressor element 1), encodes the 986 aa protein and has no specific motif or domain except for a proline-rich region at its $\mathrm{N}$-terminal side. Although this gene has been isolated in other cDNA projects, such as the National Institutes of Health Mammalian Gene Collection (MGC) Program (Strausberg et al., 2002) and the Functional Annotation of Mouse (FANTOM) Consortium (Kawai et al., 2001; Okazaki et al., 
2002b), only one study has reported on the functional aspects of this gene (Gudkov et al., 1994). In that study, a partial cDNA fragment of the Gse1 gene was isolated using expression selection of genetic suppressor elements (GSEs) associated with etoposide sensitivity. Therefore, mKIAA0182 may be involved in cell survival through a similar mechanism underlying resistance to certain drugs. On the other hand, mKIAA1039, which is identical to Garnl4 (GTPase activating RANGAP domain-like 4), encodes the Rap/ran-GAP domain predicted through automated computational analysis by the National Center for Biotechnology Information (NBCI). It is also orthologous to human Rap1 GTPase activating protein 2b (Rap1GAP2). mKIAA1039 has a moderate similarity to Rap1GAP1 (identities $=48.8 \%$ ungapped), which is the most recently identified GTPase-activating protein (GAP) responsible for the activation of Rap1 (Arthur et al., 2004; Bivona et al., 2004; Daumke et al., 2004; Hogan et al., 2004; Prevost et al., 2004). Therefore, mKIAA1039, like Rap1GAP1, might act as a GAP and consequently modulate cell adhesion and cell-cell contacts.

Many studies have been performed on cancer cell differentiation induced by RA. Using several types of cell lines, hundreds of genes were previously reported as RA-regulated genes. However, these genes are involved in 
functionally diverse categories; predominant downregulation of gene expression is common among these previous studies. For instance, Truckenmiller et. al. reported that $19 \%$ of the genes spotted on a human $15 \mathrm{~K}$ microarray $(15,000$ genes) were downregulated and $9 \%$ were upregulated $6 \mathrm{~h}$ after RA treatment of SH-SY5Y neuroblastoma cell line (Truckenmiller et al., 2001). Li et. al. also reported that 52 downregulated and 34 upregulated genes $48 \mathrm{~h}$ after RA treatment by huGene microarray (Affymetrix) analysis of Weri-RB-1 retinoblastoma cell lines ( $\mathrm{Li}$ et al., 2003). Likewise, our data demonstrated a time-dependent regulation with about $1 / 4$ being upregulated and $3 / 4$ downregulated after RA treatment. Similarly predominant downregulation of gene expression has been reported even in cell lines expressing acute promyelocytic leukemia (PML)-associated fusion proteins, such as PML/RAR $\alpha$ (Alcalay et al., 2003; Park et al., 2003). The suppression of proliferation is an obligatory step in the differentiation of cancer cells. Therefore, predominant downregulation of gene expression seems to be essential at a relatively early stage of the differentiation.

We attempted to identify the relationships among the genes whose expressions changed temporally during RA treatment by searching for the cellular pathways using pathway analysis software. However, the use of these tools 
allows us only to identify pathways constructed by known interactions and by the regulation of gene networks. Nevertheless, these tools do provide additional confidence in the selected genes as well as the key to the interpretation of microarray results. Furthermore, this strategy provides clues to other genes in the same pathway, even with genes that have not been analyzed or did not show significant changes according to the microarray analysis. For instance, we demonstrated the participation of the network of cell death and morphology in RA-treated Neuro2A cells. Some of the members of this pathway were previously identified as either direct or indirect targets of RA (Bertagnolo et al., 1998; Sarkar and Sharma, 2002; Bertagnolo et al., 2004; Farooqui et al., 2004). Although these previous data were obtained from experiments using long-time exposure to RA, our data confirm their importance, even in the early stage of RA treatment. 


\section{Acknowledgments}

We would like to thank Emiko Suzuki and Dr. Manabu Nakayama (Kazusa DNA

Research Institute) for providing Neuro2A cells. This study was supported by the CREATE Program (Collaboration of Regional Entities for the Advancement of Technological Excellence) from JST (Japan Science and Technology Corporation). 


\section{References}

Alcalay, M., Meani, N., Gelmetti, V., Fantozzi, A., Fagioli, M., Orleth, A.,

Riganelli, D., Sebastiani, C., Cappelli, E., Casciari, C., Sciurpi, M.T.,

Mariano, A.R., Minardi, S.P., Luzi, L., Muller, H., Di Fiore, P.P., Frosina,

G. and Pelicci, P.G.: Acute myeloid leukemia fusion proteins deregulate

genes involved in stem cell maintenance and DNA repair. J Clin Invest 112

(2003) 1751-61.

Arthur, W.T., Quilliam, L.A. and Cooper, J.A.: Rap1 promotes cell spreading by localizing Rac guanine nucleotide exchange factors. J Cell Biol 167 (2004)

$111-22$

Bertagnolo, V., Marchisio, M., Volinia, S., Caramelli, E. and Capitani, S.: Nuclear association of tyrosine-phosphorylated Vav to phospholipase C-gamma1 and phosphoinositide 3-kinase during granulocytic differentiation of HL-60 cells. FEBS Lett 441 (1998) 480-4.

Bertagnolo, V., Brugnoli, F., Marchisio, M., Celeghini, C., Carini, C. and Capitani, S.: Association of PI 3-K with tyrosine phosphorylated Vav is essential for its activity in neutrophil-like maturation of myeloid cells. Cell Signal 16 (2004) 423-33. 
Bivona, T.G., Wiener, H.H., Ahearn, I.M., Silletti, J., Chiu, V.K. and Philips, M.R.: Rap1 up-regulation and activation on plasma membrane regulates $\mathrm{T}$ cell adhesion. J Cell Biol 164 (2004) 461-70.

Daumke, O., Weyand, M., Chakrabarti, P.P., Vetter, I.R. and Wittinghofer, A.: The GTPase-activating protein Rap1GAP uses a catalytic asparagine. Nature 429 (2004) 197-201.

de Brevern, A.G., Hazout, S. and Malpertuy, A.: Influence of microarrays experiments missing values on the stability of gene groups by hierarchical clustering. BMC Bioinformatics 5 (2004) 114.

Farooqui, A.A., Antony, P., Ong, W.Y., Horrocks, L.A. and Freysz, L.: Retinoic acid-mediated phospholipase A2 signaling in the nucleus. Brain Res Brain Res Rev 45 (2004) 179-95.

Gudkov, A.V., Kazarov, A.R., Thimmapaya, R., Axenovich, S.A., Mazo, I.A. and Roninson, I.B.: Cloning mammalian genes by expression selection of genetic suppressor elements: association of kinesin with drug resistance and cell immortalization. Proc Natl Acad Sci U S A 91 (1994) 3744-8.

Hogan, C., Serpente, N., Cogram, P., Hosking, C.R., Bialucha, C.U., Feller, S.M., Braga, V.M., Birchmeier, W. and Fujita, Y.: Rap1 regulates the formation 
of E-cadherin-based cell-cell contacts. Mol Cell Biol 24 (2004) 6690-700.

Kawai, J., Shinagawa, A., Shibata, K., Yoshino, M., Itoh, M., Ishii, Y., Arakawa, T., Hara, A., Fukunishi, Y., Konno, H., Adachi, J., Fukuda, S., Aizawa, K., Izawa, M., Nishi, K., Kiyosawa, H., Kondo, S., Yamanaka, I., Saito, T., Okazaki, Y., Gojobori, T., Bono, H., Kasukawa, T., Saito, R., Kadota, K., Matsuda, H., Ashburner, M., Batalov, S., Casavant, T., Fleischmann, W., Gaasterland, T., Gissi, C., King, B., Kochiwa, H., Kuehl, P., Lewis, S., Matsuo, Y., Nikaido, I., Pesole, G., Quackenbush, J., Schriml, L.M., Staubli, F., Suzuki, R., Tomita, M., Wagner, L., Washio, T., Sakai, K., Okido, T., Furuno, M., Aono, H., Baldarelli, R., Barsh, G., Blake, J., Boffelli, D., Bojunga, N., Carninci, P., de Bonaldo, M.F., Brownstein, M.J., Bult, C., Fletcher, C., Fujita, M., Gariboldi, M., Gustincich, S., Hill, D., Hofmann, M., Hume, D.A., Kamiya, M., Lee, N.H., Lyons, P., Marchionni, L., Mashima, J., Mazzarelli, J., Mombaerts, P., Nordone, P., Ring, B., Ringwald, M., Rodriguez, I., Sakamoto, N., Sasaki, H., Sato, K.,

Schonbach, C., Seya, T., Shibata, Y., Storch, K.F., Suzuki, H., Toyo-oka, K., Wang, K.H., Weitz, C., Whittaker, C., Wilming, L., Wynshaw-Boris, A., Yoshida, K., Hasegawa, Y., Kawaji, H., Kohtsuki, S. and Hayashizaki, Y.: 
Functional annotation of a full-length mouse cDNA collection. Nature 409

(2001) 685-90.

Koga, H., Yuasa, S., Nagase, T., Shimada, K., Nagano, M., Imai, K., Ohara, R., Nakajima, D., Murakami, M., Kawai, M., Miki, F., Magae, J., Inamoto, S., Okazaki, N. and Ohara, O.: A comprehensive approach for establishment of the platform to analyze functions of KIAA proteins II: public release of inaugural version of InGaP database containing gene/protein expression profiles for 127 mouse KIAA genes/proteins. DNA Res 11 (2004) 293-304.

Li, A., Zhu, X., Brown, B. and Craft, C.M.: Gene expression networks underlying retinoic acid-induced differentiation of human retinoblastoma cells. Invest Ophthalmol Vis Sci 44 (2003) 996-1007.

Mader, S., Leroy, P., Chen, J.Y. and Chambon, P.: Multiple parameters control the selectivity of nuclear receptors for their response elements. Selectivity and promiscuity in response element recognition by retinoic acid receptors and retinoid X receptors. J Biol Chem 268 (1993) 591-600.

Marshall, H., Morrison, A., Studer, M., Popperl, H. and Krumlauf, R.: Retinoids and Hox genes. Faseb J 10 (1996) 969-78. 
Nakajima, D., Okazaki, N., Yamakawa, H., Kikuno, R., Ohara, O. and Nagase, T.: Construction of expression-ready cDNA clones for KIAA genes: manual curation of 330 KIAA cDNA clones. DNA Res 9 (2002) 99-106.

Nomura, N., Miyajima, N., Sazuka, T., Tanaka, A., Kawarabayasi, Y., Sato, S., Nagase, T., Seki, N., Ishikawa, K. and Tabata, S.: Prediction of the coding sequences of unidentified human genes. I. The coding sequences of 40 new genes (KIAA0001-KIAA0040) deduced by analysis of randomly sampled cDNA clones from human immature myeloid cell line KG-1. DNA Res 1 (1994) 27-35.

Okazaki, N., Kikuno, R., Ohara, R., Inamoto, S., Hara, Y., Nagase, T., Ohara, O. and Koga, H.: Prediction of the coding sequences of mouse homologues of KIAA gene: I. The complete nucleotide sequences of 100 mouse KIAA-homologous cDNAs identified by screening of terminal sequences of cDNA clones randomly sampled from size-fractionated libraries. DNA Res 9 (2002a) 179-88.

Okazaki, Y., Furuno, M., Kasukawa, T., Adachi, J., Bono, H., Kondo, S., Nikaido, I., Osato, N., Saito, R., Suzuki, H., Yamanaka, I., Kiyosawa, H., Yagi, K., Tomaru, Y., Hasegawa, Y., Nogami, A., Schonbach, C., Gojobori, T., 
Baldarelli, R., Hill, D.P., Bult, C., Hume, D.A., Quackenbush, J., Schriml,

L.M., Kanapin, A., Matsuda, H., Batalov, S., Beisel, K.W., Blake, J.A.,

Bradt, D., Brusic, V., Chothia, C., Corbani, L.E., Cousins, S., Dalla, E.,

Dragani, T.A., Fletcher, C.F., Forrest, A., Frazer, K.S., Gaasterland, T.,

Gariboldi, M., Gissi, C., Godzik, A., Gough, J., Grimmond, S., Gustincich,

S., Hirokawa, N., Jackson, I.J., Jarvis, E.D., Kanai, A., Kawaji, H.,

Kawasawa, Y., Kedzierski, R.M., King, B.L., Konagaya, A., Kurochkin,

I.V., Lee, Y., Lenhard, B., Lyons, P.A., Maglott, D.R., Maltais, L.,

Marchionni, L., McKenzie, L., Miki, H., Nagashima, T., Numata, K.,

Okido, T., Pavan, W.J., Pertea, G., Pesole, G., Petrovsky, N., Pillai, R.,

Pontius, J.U., Qi, D., Ramachandran, S., Ravasi, T., Reed, J.C., Reed, D.J.,

Reid, J., Ring, B.Z., Ringwald, M., Sandelin, A., Schneider, C., Semple,

C.A., Setou, M., Shimada, K., Sultana, R., Takenaka, Y., Taylor, M.S.,

Teasdale, R.D., Tomita, M., Verardo, R., Wagner, L., Wahlestedt, C., Wang,

Y., Watanabe, Y., Wells, C., Wilming, L.G., Wynshaw-Boris, A.,

Yanagisawa, M., et al.: Analysis of the mouse transcriptome based on

functional annotation of 60,770 full-length cDNAs. Nature 420 (2002b)

563-73. 
Okazaki, N., Kikuno, R., Ohara, R., Inamoto, S., Aizawa, H., Yuasa, S., Nakajima, D., Nagase, T., Ohara, O. and Koga, H.: Prediction of the coding sequences of mouse homologues of KIAA gene: II. The complete nucleotide sequences of 400 mouse KIAA-homologous cDNAs identified by screening of terminal sequences of cDNA clones randomly sampled from size-fractionated libraries. DNA Res 10 (2003a) 35-48.

Okazaki, N., Kikuno, R., Ohara, R., Inamoto, S., Koseki, H., Hiraoka, S., Saga, Y., Nagase, T., Ohara, O. and Koga, H.: Prediction of the coding sequences of mouse homologues of KIAA gene: III. the complete nucleotide sequences of 500 mouse KIAA-homologous cDNAs identified by screening of terminal sequences of cDNA clones randomly sampled from size-fractionated libraries. DNA Res 10 (2003b) 167-80.

Okazaki, N., Kikuno, R., Ohara, R., Inamoto, S., Koseki, H., Hiraoka, S., Saga, Y., Kitamura, H., Nakagawa, T., Nagase, T., Ohara, O. and Koga, H.: Prediction of the coding sequences of mouse homologues of FLJ genes: the complete nucleotide sequences of 110 mouse FLJ-homologous cDnas identified by screening of terminal sequences of cDNA clones randomly sampled from size-fractionated libraries. DNA Res 11 (2004a) 127-35. 
Okazaki, N., R, F.K., Ohara, R., Inamoto, S., Koseki, H., Hiraoka, S., Saga, Y., Seino, S., Nishimura, M., Kaisho, T., Hoshino, K., Kitamura, H., Nagase, T., Ohara, O. and Koga, H.: Prediction of the coding sequences of mouse homologues of KIAA gene: IV. The complete nucleotide sequences of 500 mouse KIAA-homologous cDNAs identified by screening of terminal sequences of cDNA clones randomly sampled from size-fractionated libraries. DNA Res 11 (2004b) 205-18.

Park, D.J., Vuong, P.T., de Vos, S., Douer, D. and Koeffler, H.P.: Comparative analysis of genes regulated by PML/RAR alpha and PLZF/RAR alpha in response to retinoic acid using oligonucleotide arrays. Blood 102 (2003) 3727-36.

Prevost, N., Woulfe, D.S., Tognolini, M., Tanaka, T., Jian, W., Fortna, R.R., Jiang, H. and Brass, L.F.: Signaling by ephrinB1 and Eph kinases in platelets promotes Rap1 activation, platelet adhesion, and aggregation via effector pathways that do not require phosphorylation of ephrinB1. Blood 103 (2004) 1348-55.

Riboni, L., Prinetti, A., Bassi, R., Caminiti, A. and Tettamanti, G.: A mediator role of ceramide in the regulation of neuroblastoma Neuro2a cell 
differentiation. J Biol Chem 270 (1995) 26868-75.

Sarkar, S.A. and Sharma, R.P.: Expression of selected apoptosis related genes, MIF, IGIF and TNF alpha, during retinoic acid-induced neural differentiation in murine embryonic stem cells. Cell Struct Funct 27 (2002) 99-107.

Schilling, T.F. and Knight, R.D.: Origins of anteroposterior patterning and Hox gene regulation during chordate evolution. Philos Trans R Soc Lond B Biol Sci 356 (2001) 1599-613.

Shea, T.B., Fischer, I. and Sapirstein, V.S.: Effect of retinoic acid on growth and morphological differentiation of mouse NB2a neuroblastoma cells in culture. Brain Res 353 (1985) 307-14.

Strausberg, R.L., Feingold, E.A., Grouse, L.H., Derge, J.G., Klausner, R.D., Collins, F.S., Wagner, L., Shenmen, C.M., Schuler, G.D., Altschul, S.F., Zeeberg, B., Buetow, K.H., Schaefer, C.F., Bhat, N.K., Hopkins, R.F., Jordan, H., Moore, T., Max, S.I., Wang, J., Hsieh, F., Diatchenko, L., Marusina, K., Farmer, A.A., Rubin, G.M., Hong, L., Stapleton, M., Soares, M.B., Bonaldo, M.F., Casavant, T.L., Scheetz, T.E., Brownstein, M.J., Usdin, T.B., Toshiyuki, S., Carninci, P., Prange, C., Raha, S.S., Loquellano, 
N.A., Peters, G.J., Abramson, R.D., Mullahy, S.J., Bosak, S.A., McEwan, P.J., McKernan, K.J., Malek, J.A., Gunaratne, P.H., Richards, S., Worley, K.C., Hale, S., Garcia, A.M., Gay, L.J., Hulyk, S.W., Villalon, D.K., Muzny, D.M., Sodergren, E.J., Lu, X., Gibbs, R.A., Fahey, J., Helton, E., Ketteman, M., Madan, A., Rodrigues, S., Sanchez, A., Whiting, M., Young, A.C., Shevchenko, Y., Bouffard, G.G., Blakesley, R.W., Touchman, J.W., Green, E.D., Dickson, M.C., Rodriguez, A.C., Grimwood, J., Schmutz, J., Myers, R.M., Butterfield, Y.S., Krzywinski, M.I., Skalska, U., Smailus, D.E., Schnerch, A., Schein, J.E., Jones, S.J. and Marra, M.A.: Generation and initial analysis of more than 15,000 full-length human and mouse cDNA sequences. Proc Natl Acad Sci U S A 99 (2002) 16899-903.

Truckenmiller, M.E., Vawter, M.P., Cheadle, C., Coggiano, M., Donovan, D.M., Freed, W.J. and Becker, K.G.: Gene expression profile in early stage of retinoic acid-induced differentiation of human SH-SY5Y neuroblastoma cells. Restor Neurol Neurosci 18 (2001) 67-80.

Wang, J. and Yen, A.: A novel retinoic acid-responsive element regulates retinoic acid-induced BLR1 expression. Mol Cell Biol 24 (2004) 2423-43. 


\section{Figure legends}

Fig. 1. Temporal response of mKIAA gene expression induced by RA for 0-24

h. Temporal gene expression patterns of 38 mKIAA genes exhibiting a reproducible change $>1.7$ fold (relative to time 0 ) after RA treatment are arranged in order of hierarchical clustering taken from Ward's method. The branch lengths were drawn proportional to the distances of distinct genes. Each gene is represented by a single row of colored boxes; each time point is represented by a single column. Each box represents the expression level of an individual gene at each time point $($ red $=$ upregulated, black $=$ unchanged, green $=$ downregulated $)$. Accession number, gene name, and alias are also indicated to the right of each row. The aliases include gene names only predicted by automated computational analysis of NCBI and by other cDNA projects.

Fig. 2. Confirmation of microarray results by semi-quantitative RT-PCR

analysis. (A) The Agilent 2100 Bioanalyzer observed only PCR products of sufficient size. This result is representative of three independent experiments. (B) The raw data were normalized against control samples (15 bp and $600 \mathrm{bp}$ DNA fragments) and then calibrated by each point of Gapd expression. The calibrated data were plotted ( $\square$ ) together with the oligonucleotide microarray data 
( $\square$ ).

Fig. 3. Pathway of cell death and morphology related to retinoic acid-induced neurite outgrowth of Neuro2A cells. (A) Schematic representation of the pathway of cell death and morphology, including six mKIAA genes (in green). The genes are essentially represented by ellipses. A modification of the shape refers to a gene's functions (e.g., an eclipsed shape represents protein kinase). The interactions and regulations among the genes are illustrated by the different lines of connection. These data are freely available through our InCeP (Intracellular pathway based on mKIAA protein-protein interactions) database (http://www.kazusa.or.jp/create). Abbreviation of gene symbols: PTPRA, protein tyrosine phosphatase receptor type A; ITGAV, integrin $\alpha \mathrm{V}$; APS, adaptor protein with pleckstrin homology and src homology 2 domains; GRB, growth factor receptor-bound protein; DNM1, dynamin 1; FRS2, fibroblast growth factor receptor substrate 2; GRB7, growth factor receptor-bound protein 7; PLCG1, phospholipase C $\gamma$ 1; SOCS1, suppressor of cytokine signaling 1; PTPN, protein tyrosine phosphatase non-receptor type; SORBS1, sorbin and SH3 domain containing 1; GAB1, GRB2-associated binding protein 1; PIK3R1, phosphoinositide-3-kinase regulatory subunit polypeptide 1 (p85 $\alpha$ ); MAP4K1, 
mitogen-activated protein kinase kinase kinase kinase 1; REPS2, RALBP1 associated Eps domain containing 2; PTK2, PTK2 protein tyrosine kinase 2; RASA1, RAS p21 protein activator 1; GGA2, golgi associated, $\gamma$ adaptin ear containing ARF binding protein 2; CASP, caspase; RIPK1, receptor-interacting serine-threonine kinase 1; HNRPC, heterogeneous nuclear ribonucleoprotein $\mathrm{C}$. (B) Temporal gene expression patterns of six mKIAA genes mapped on the pathway by Ingenuity Pathway Analysis software. The data were extracted from data in Fig. 1 and then rearranged in accordance with the pathway. 
Table 1

The primer sequences and the conditions for amplification of Gapd and mKIAA genes

\begin{tabular}{cccccc}
\hline Gene name & $\begin{array}{c}\text { Forward primer } \\
\left(5^{\prime} \rightarrow 3^{\prime}\right)\end{array}$ & $\begin{array}{c}\text { Reverse primer } \\
\left(5^{\prime} \rightarrow 3^{\prime}\right)\end{array}$ & $\begin{array}{c}\text { Product } \\
\text { size }(\mathrm{bp})\end{array}$ & $\begin{array}{c}\text { Annealing } \\
\text { temp. }\end{array}$ & $\begin{array}{c}\text { Extention } \\
\text { teme }\end{array}$ \\
& time $(\mathrm{sec})$ & $\begin{array}{c}\text { PCR } \\
\text { cycles }\end{array}$ \\
\hline Gapd & AAC TCC CAC TCT TCC ACC T & CAC CAC CCT GTT GCT GTA G & 111 & 58 & 5 \\
mKIAA0059 & AAG TGG CAG AGA GGA AGA T & ACC AGG GAG AGA TGA AGT T & 213 & 56 & 10 \\
mKIAA0182 & CAT AGA AGA GCA AAA CCT GG & TTC TGA CTC CGA AGC TCC & 129 & 57 & 7 \\
mKIAA1039 & CAT CCA CAA CCT CGC CCT T & GGG AGT TTC TGC TTT TGG C & 138 & 57 & 6 \\
mKIAA1209 & ACC GTC CAG TCA GCA TAG G & CGT TAC TGT AGG GCG AAT G & 259 & 60 & 25 \\
\hline
\end{tabular}


Table 2

Identified RAREs at the regulatory genomic regions of mKIAA0182 and mKIAA1039 genes

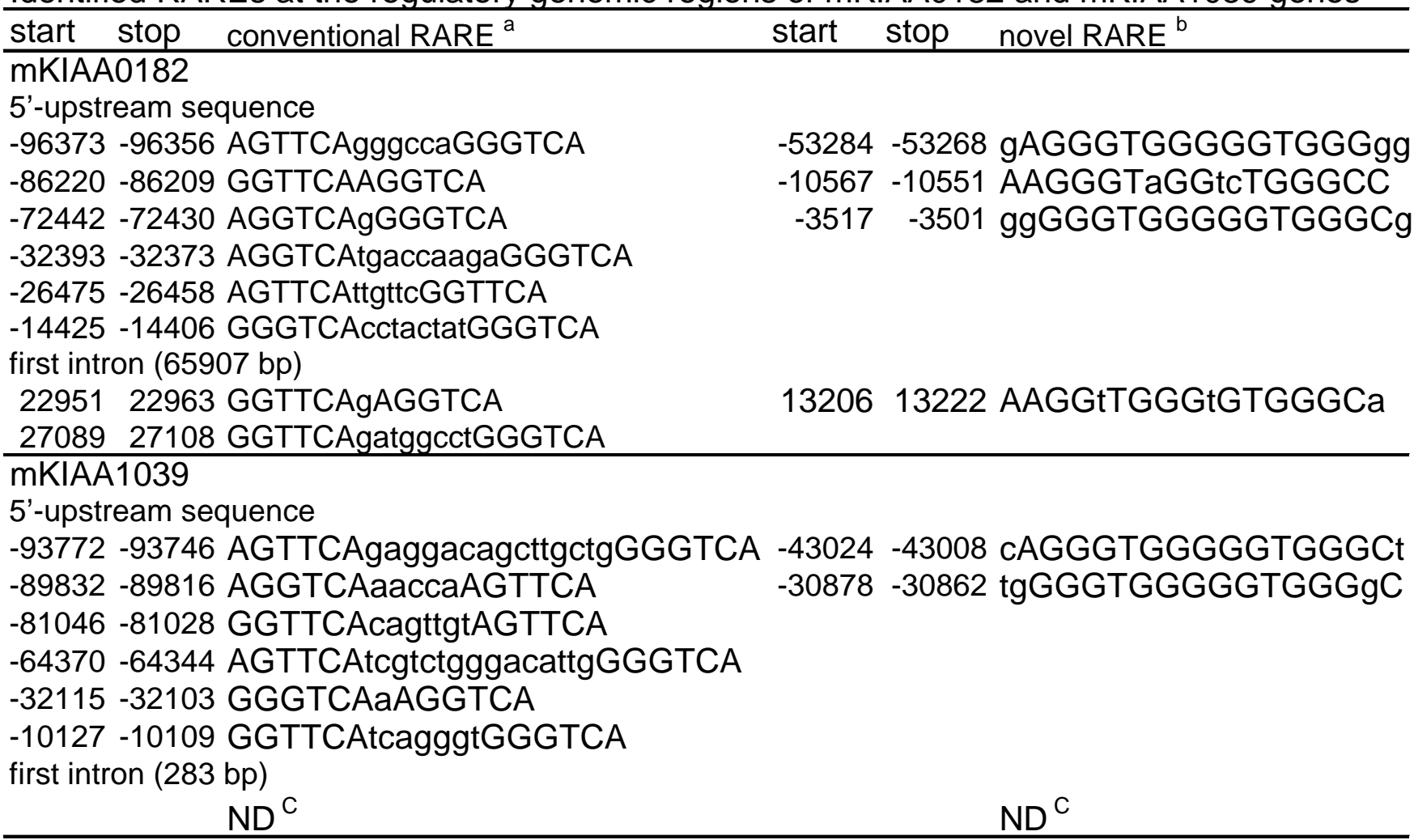

${ }^{a}$ Spacer sequences between A/GGT/GTCA direct repeat are denoted by lowercase letters.

${ }^{\mathrm{b}}$ Unmatched nucleotide sequences are denoted by lowercase letters.

${ }^{\mathrm{C}} \mathrm{ND}$, not detected. 

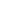
fig 3

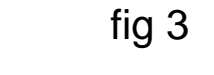

\section{II cell membrane}

\section{cytoplasm}

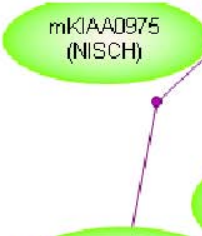

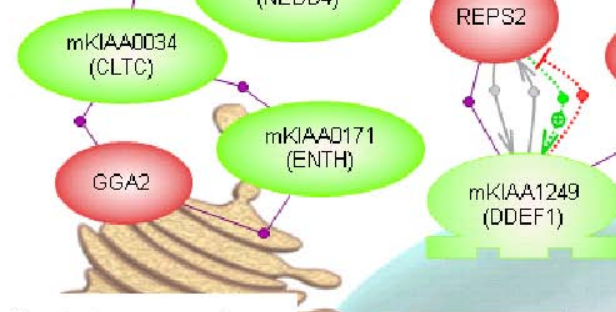

Golgi apparatus

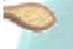

\section{nucleus}

\section{GRB2}

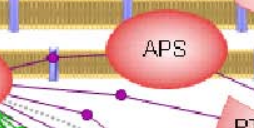

ITGAV
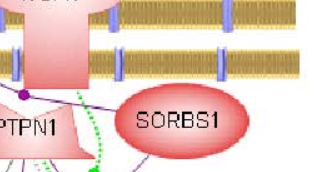

mKIAADOG3 FRS2 GRBT of (SOCS1 PTPN

$\begin{array}{lllllll}0 & 1 & 3 & 6 & 12 & 24 & \text { Accsession Gene Name Alias Name }\end{array}$

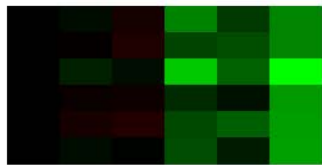
AK122412 mKIAA0975 Nischarin AK122203 mKIAA0093 E3 ubiquitin-protein ligase Nedd-4 AK122193 mKIAA0034 Clathrin heavy chain AB093212 mKIAA0171 Epsin 4 AK122477 mKIAA1249 Development and differentiation-enhancing factor 1 AK122342 mKIAA0670 Apoptotic chromatin condensation inducer in the nucleus

MKIAADG70 (ACIN1)

\subsection{5}

